\title{
Cancer mortality trends among middle-aged men and women in Nigeria: data from the WHO cancer mortality database
}

\author{
Kelechi Martins Nworie
}

Department of Clinical Pharmacy and Pharmacy Administration, University of Nigeria, Nsukka, Nigeria

Submitted: 29 June 2018

Accepted: 10 July 2018

Arch Med Sci Aging 2018; 1: e8-e11

DOI: https://doi.org/10.5114/amsa.2018.77627

Copyright $\odot 2018$ Termedia \& Banach

\section{Abstract}

Introduction: Cancer is a common global disease characterized by regional variations and late clinical presentations in most developing countries including Nigeria. In 2008, Nigeria was one of the countries with the highest cancer rates in Africa and contributed to $15 \%$ of estimated new cases. Despite the threat that cancer poses in sub-Saharan Africa, few countries have established implementation for control of the disease. This study analyses the trends and peculiarity of cancer in the Nigerian population, by comparing and contrasting its prevalence among males and females. We also present estimates of cancer incidence in the Nigerian population.

Material and methods: Data on cases and cancer mortality rates were obtained from the WHO cancer mortality database, Health statistics and information systems. The data were analyzed using SPSS Statistics v. 17.

Results: A slightly declining cancer mortality rate was observed from 2000 to 2012. A higher mortality rate was observed among women than men. The highest incidence of cancer among men was observed for prostate and liver cancer, while breast and cervix uteri cancer had the highest incidence among females.

Conclusions: Though a slight decline in cancer mortality was observed in the study, the cancer mortality rate in Nigeria is still high. It is important to identify factors that promote cancer control and ensure the next steps towards further eradication of cancer and cancer-related diseases in Nigeria.

Key words: cancer, mortality, men and women, Nigeria.

\section{Introduction}

Globally, cancer has become a major source of morbidity and mortality [1]. In 2008, there were approximately 12.7 million cases and 7.6 million cancer-related deaths [2] with $56 \%$ of the newly reported cases occurring in developing countries. It is projected that $70 \%$ of all new cases by 2030 will be found in developing countries [3]. Developing or low income countries have recently been the regions with predominantly the highest cancer prevalence in the world, and the highest rates of undiagnosed and untreated cancer-related diseases [4, 5]. Most of the increase in cancer incidence is primarily due to population growth and life expectancy [6]. The peculiarity of cancer disease in Nigeria has several facets. For instance, it is estimated that 100,000 new cases of cancer occur every

\author{
Corresponding author: \\ Kelechi Martins Nworie \\ Department of Clinical \\ Pharmacy and \\ Pharmacy Administration \\ University of Nigeria \\ 410001 Nsukka, Nigeria \\ Phone: +234(0)8063728781 \\ E-mail: \\ nworiekelechimartins@gmail. \\ com
}


year [2]. In 2008, Nigeria represented $15 \%$ of the 681,000 new cases of cancer that occurred in Africa [1]. Since three decades, public awareness and sensitization by non-Governmental and Governmental organizations through collaboration have been the major evidence to combat the disease in developing countries [7, 8]. Also, diagnosis of cancer was characterized by late clinical presentation in an advanced stage of the disease, when only chemotherapy and palliative care could be given. The majority of these patients with cancer present with stage III or IV disease, which is associated with lower survival rates and higher mortality rates $[9,10]$.

Despite the initiation of a program of National System of Cancer Registries in 2009 by the Nigerian Federal Ministry of Health (FMOH) and the Institute of Human Virology Nigeria (IHVN), there is dearth of data and sparse literature on the trends and peculiarity of cancer in Nigeria. Lower income countries use a hospital-based cancer registry and the WHO database as the fundamental source of information on cancer.

The aim of this article is to compare and contrast the trends of cancer mortality among males and females in Nigeria, and to establish the uniqueness of this disease in the Nigerian population

\section{Material and methods}

Data on both cancer information and mortality rates utilized for this study are based on the 2014

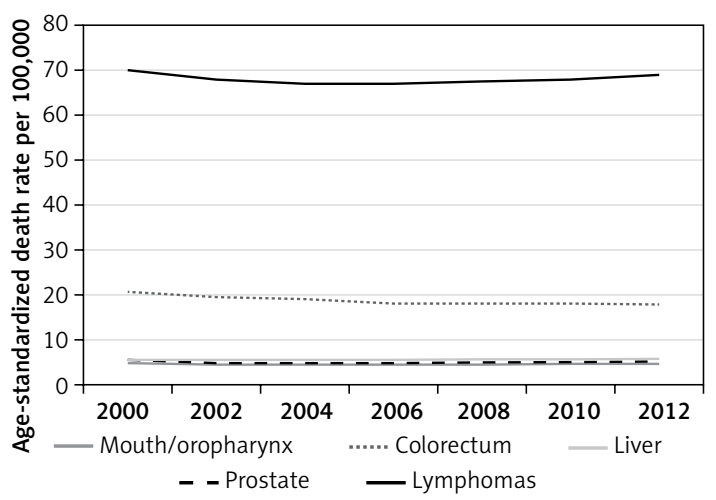

Figure 1. Age-standardized cancer mortality trends among men, Nigeria

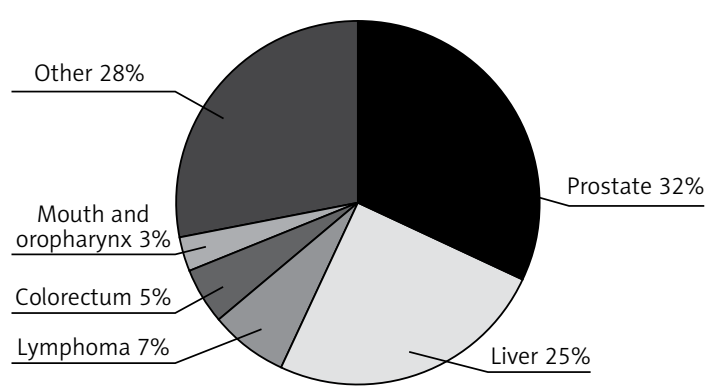

Figure 3. Cancer mortality among men, Nigeria (deaths $=30,400$ )
WHO mortality database, Health statistics and information systems [11].

\section{Statistical analysis}

The analysis was conducted using SPSS Statistics v. 17 . The mortality rates were presented as "standardized mortality rate per 100,000 populations".

\section{Results}

Figures 1 and 2 present the cancer mortality time trends among middle-aged men and women in Nigeria from 2000 to 2012 . The mortality of liver cancer among men was significantly higher than among women. Prostate cancer in men $(70 / 100,000)$ was significantly more frequent than breast cancer $(30 / 100,000)$ in women. Among women, frequency of cervix uteri cancer decreased progressively from the year 2000 to 2012. The observed mortality rate of lymphomas was similar in both sexes. The percentage mortality of different types of cancers is represented in Figures 3 and 4. Prostate (32\%) and breast cancers $(34 \%)$ caused the most deaths in men and women respectively. The mortality from lung cancer was significantly higher in men (25\%) than in women (10\%). Figures 5 and 6 also present the cancer incidence among men and women respectively. The most common types of cancer

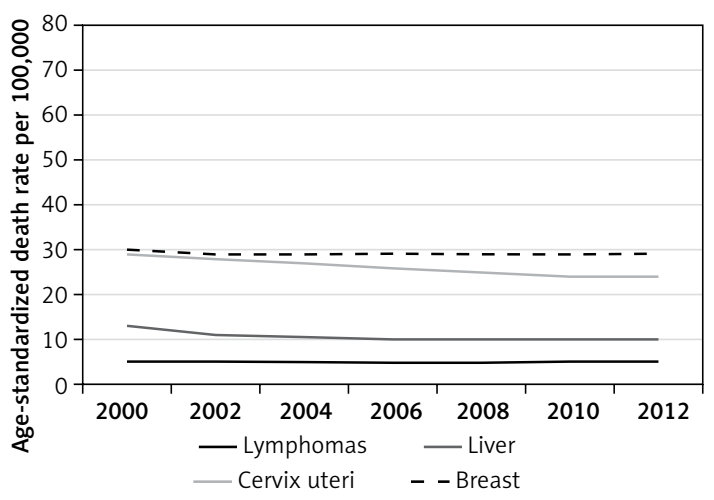

Figure 2. Age-standardized cancer mortality trends among women, Nigeria

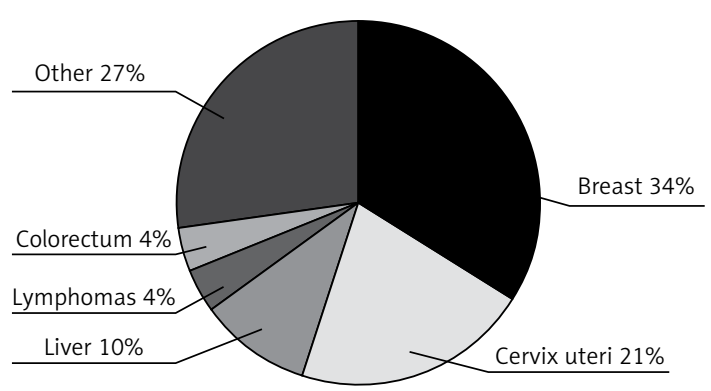

Figure 4. Cancer mortality among women, Nigeria (deaths $=38,800)$ 


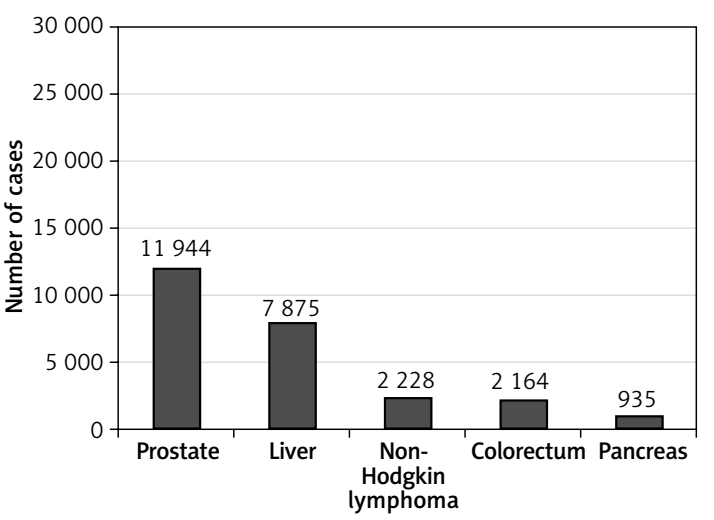

Figure 5. Cancer incidence among men, Nigeria

in men were prostate and liver cancer. For women, the most common cancers were breast and cervix uteri cancer.

\section{Discussion}

Several decades ago, nearing the beginning of the $21^{\text {st }}$ century, Nigeria was one of the leading countries for cancer mortality in Africa [1]. During this period it had the highest cancer incidence in Africa, which was more predominant among men $[1,2]$. However, the breakthrough came years after. In the years 2000-2012, Nigeria had a progressive, significant decline in cancer mortality among both men and women. Prevalence of cancer in $\mathrm{Ni}$ geria was consistently higher in women than in men. This could be attributed to the higher risk factors among women than men. For instance, the current cancer risk factor from tobacco smoking and total alcohol per capita consumption is higher in women than men [12]. Our study reveals that the commonest cancers in Nigeria from 2000 to 2012 were prostate among males and breast cancer among women. We also observed a slight decline in cancer mortality during this period.

While Nigeria can celebrate the success of declining prevalence of cancer, it must not be forgotten that the diminished peculiarity of the $\mathrm{Ni}$ gerian cancer health and policy system. Though there is a national cancer registry, there is a lack of effective cancer plans, monitoring and surveillance [13]. There is also a lack of operational policy, strategy or action to reduce the burden of tobacco use [14], and complete absence of bans on advertising, promoting and sponsorship which increases risk of cancer [15]. Cancer screening and early detection of cancer are not generally available at the public primary health care level $[16,17]$. Cancer treatments such as radiotherapy and chemotherapy are not generally available in the public health system [18]. Palliative care such as community/home care for people with advanced stage cancer is also not generally available [19].

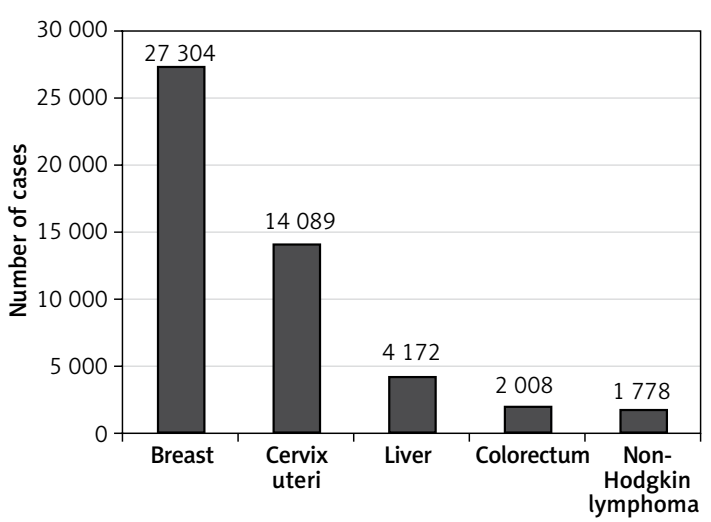

Figure 6. Cancer incidence among women, Nigeria

In conclusion, we made two observations and questions from the study. The first is that cancer mortality has declined slightly over the last two decades; and what important factors promote these developments in Nigeria? The second is that cancer mortality is significantly higher among men than women; and what are the next steps towards further eradication of cancer and cancer-related diseases in developing countries such as Nigeria?

\section{Conflict of interest}

The authors declare no conflict of interest.

\section{References}

1. Sylla BS, Wild CP. A million Africans a year dying from cancer by 2030: what can cancer research and control offer to the continent? Int J Cancer 2012; 130: 245-50.

2. Ferlay J, Shin HR, Bray F, Forman D, Matters C, Parkin DM. Estimates of worldwide burden of cancer in 2008: GLOBACAN 2008. Int J Cancer 2011; 127: 2893-917.

3. Boyle P, Levin B. International Agency for Research on Cancer. World Cancer Report 2008; Lyon, France. 2008.

4. Jones SB. Cancer in developing world: a call to action. BMJ 1999; 319: 505-8.

5. Sharma V, Kerr SH, Kawar Z, Kerr DJ. Challenges of cancer control in developing countries. Future Oncol 2011; 7: 1213-22.

6. Lyerly HK, Abernethy AP, Stockler MR, et al. Need for global partnership in cancer care researchers attending the 2010 Australia and Asia Pacific Clinical Oncology Research Development Workshop. J Oncol Pract 2011; 7: 324-9.

7. Salako O, Roberts AA, Isibor VI, Babatunde O, Fatiregun O, Nwogu CN. Innovative breast cancer awareness and advocacy campaign. J Glob Oncol 2017; 3: 169-76.

8. Odedina FT, Rodrigues B. Cancer advocacy in Africa: case studies of innovative practices. Infect Agent Cancer 2013; 8 (Suppl 1): S7.

9. Scheel JR, Molina Y, Patrick DL, et al. Breast cancer dowstaging practices and breast health messaging preferences among a community sample of urban and rural Ugandan women. J Glob Oncol 2017; 3: 105-13.

10. McPhail S, Ellis-Brookes L, Shelton J, et al. Emergency presentation of cancer and short-term mortality. $\mathrm{Br}$ J Cancer 2013; 109: 2027-34. 
11. World Health Organization Mortality Database. Health and statistic information systems, 2014.

12. Yue Y, Hong L, Guo L, et al. Gender differences in the association between cigarette smoking, alcohol consumption and depressive symptoms: a cross sectional study among Chinese adolescents. Sci Rep 2915; 5: 17959.

13. Welcome MO. The Nigerian health care system: need for integrating adequate medical intelligence and surveillance systems. J Pharm Bioallied Sci 2011; 3: 470-8.

14. Njaka SRN. A systematic review of incidence of cancer and challenges to its treatment in Nigeria. J Cancer Sci Ther 2016; 8: 286-8.

15. Chido-Amauoyi OG, Mantey DS, Clendennen SL, Perez A. Association of tobacco advertising, promotion and sponsorship (TAPS) exposure and cigarette use among Nigerian adolescents: implications for current practices, products and policies. BMJ Glob Health 2017; 2 e000357.

16. Sowemimo OO, Ojo OO, Fasubaa OB. Cervical cancer screening and practice in low resources countries: $\mathrm{Ni}$ geria as a case study. Trop J Obstet Gynaecol 2017; 34: 170-6.

17. Ishola F, Omole O. A vision for improved cancer screening in Nigeria. Lancet Global Health 2016; 4: e359-60.

18. Onyeka TC. Palliative care in Enugu, Nigeria: challenges to a new practice. Indian J Palliat Care 2011; 17: 131-6.

19. Olaitan S, Oladayo A, Ololade M. Palliative care: supporting adult cancer patients in Ibadan, Nigeria. J Palliat Care Med 2016; 6: 258. 